Article

\title{
Current Status Investigation and Predicting Carbon Dioxide Emission in Latin American Countries by Connectionist Models
}

\author{
Mohammad Hossein Ahmadi ${ }^{1,+}$, Mohammad Dehghani Madvar ${ }^{2,+}$, Milad Sadeghzadeh ${ }^{2,+}$ (i), \\ Mohammad Hossein Rezaei ${ }^{2,+}$, Manuel Herrera ${ }^{3,+}+\left(\right.$ ) and Shahaboddin Shamshirband ${ }^{4,5, *,+(\mathbb{C})}$ \\ 1 Faculty of Mechanical Engineering, Shahrood University of Technology, Shahrood 3619995161, Iran; \\ mohammadhosein.ahmadi@gmail.com \\ 2 Department of Renewable Energies and Environmental, Faculty of New Sciences and Technologies, \\ University of Tehran, Tehran 1439957131, Iran; Dehghani.ma@ut.ac.ir (M.D.M.); \\ milad.sadeghzadeh@gmail.com (M.S.); hosinrezai@znu.ac.ir (M.H.R.) \\ 3 Institute for Manufacturing, Department of Engineering, University of Cambridge, Cambridge CB3 OFS, UK; \\ amh226@cam.ac.uk \\ 4 Department for Management of Science and Technology Development, Ton Duc Thang University, \\ Ho Chi Minh City, Vietnam \\ 5 Faculty of Information Technology, Ton Duc Thang University, Ho Chi Minh City, Vietnam \\ * Correspondence: shahaboddin.shamshirband@tdtu.edu.vn \\ $\dagger$ These authors contributed equally to this work.
}

Received: 24 March 2019; Accepted: 6 May 2019; Published: 19 May 2019

\begin{abstract}
Currently, one of the biggest concerns of human beings is greenhouse gas emissions, especially carbon dioxide emissions in developed and under-developed countries. In this study, connectionist models including LSSVM (Least Square Support Vector Machine) and evolutionary methods are employed for predicting the amount of $\mathrm{CO}_{2}$ emission in six Latin American countries, i.e., Brazil, Mexico, Argentina, Peru, Chile, Venezuela and Uruguay. The studied region is modelled based on the available input data in terms of million tons including oil (million tons), gas (million tons oil equivalent), coal (million tons oil equivalent), $R_{e w}$ (million tons oil equivalent) and Gross Domestic Product (GDP) in terms of billion U.S. dollars. Moreover, the available patents in the field of climate change mitigation in six Latin American countries, namely Brazil, Mexico, Argentina, Peru, Chile, Venezuela and Uruguay, have been reviewed and analysed. The results show that except Venezuela, all other mentioned countries have invested in renewable energy R\&D activities. Brazil and Argentina have the highest share of renewable energies, which account for $60 \%$ and $72 \%$, respectively.
\end{abstract}

Keywords: $\mathrm{CO}_{2}$; modelling; environment; South America; connectionist model

\section{Introduction}

The continuous rise of carbon dioxide emissions is a major cause of global warming. Global warming is one of the biggest and probably most difficult environmental, social and economic threats that the world has faced so far in the recent century [1]. Increasing carbon dioxide emission into the atmosphere is one of the main reasons for global warming with adverse environmental effects such as sea level rise, floods, droughts, etc. During the 20th Century, the average temperature of the Earth increased by 0.6 degrees, and it is estimated that it will increase 1-5 more degrees in the next century [2]. According to the studies conducted by the World Meteorological Organization, the average global temperature in 2015 was the highest one ever recorded. Based on research, a combination of El Niño streams and global warming resulting from human activities has led to the highest recorded 
average global temperatures in 2011-2015. The COP21 conference in Paris could be regarded as a sign of solidarity and amenability for tackling the problem of climate change. The primary aim of COP21 was to prevent the increase of global temperature under two degrees Celsius and also to limit this increase under 1.5 degrees compared to the time before industrialization. One of the outcomes of this treaty was the enactment of supporting plans for providing financial resources for countries to reconstruct damaged structures polluting the environment.

One of the substantial solutions in facing climatic changes is a reduction of carbon dioxide emission [2,3], and the best way to prevent destructive environmental outcomes is capturing and storing this gas [4]. One of the key research works in the field of carbon capture and storage technology was about analysing the potential of carbon capture and storage in power plants [5]. Due to the fact that the available systems in such power plants are the same as the kind of available capture systems in coal power stations, an estimation has been made about the reduction of greenhouse gas effects until 2030 via carbon capture and storage technology. In the first stage, researchers have found that the initiation time and dispersion rate of the technology are of importance when it comes to determining the emission reduction rate and fuel consumption for carbon capture and storage technology [6]. The influential approaches that are currently carried out are, namely, making energy systems more efficient to decrease and restrict the increasing consumption rate of fossil fuels, applying practical strategies for carbon capture and storage technologies, taking the benefits of $\mathrm{CO}_{2}$ by converting it into useful products, introducing renewable energies to the energy mix, limiting deforestation and replanting, respectively. Based on the records, the foremost sources of $\mathrm{CO}_{2}$ production, i.e., one third of global carbon dioxide production, are conventional fossil fuel power plants, oil and gas refineries [1].

Modelling the $\mathrm{CO}_{2}$ emission in order to predict the influence of other factors such as utilized energy will be helpful for researchers and policy makers to have a broad vision about future energy demand, which is entwined with a sustainable environment. The amount of $\mathrm{CO}_{2}$ production of a country is highly affected by some factors such as the transportation system, the efficiency of power plants and specifically the energy consumption pattern of residents [7-10]. Ruiz-Mendoza an Sheinbaum-Pardo [11] analysed the effect of reforms performed on the electricity generation sector and their effect on carbon dioxide production in Latin American countries. The authors monitored 1990-2006 and reported that, except Columbia, which increased its capacity for renewable energies, specifically in the hydropower sector, the other countries in this region decreased the installation capacity of renewable sites. Therefore, the amount of $\mathrm{CO}_{2}$ emission has remained almost constant in other countries. Jardon et al. [12] proposed an empirical correlation between the production of carbon dioxide (per capita) and economic issues. In this study, the authors analysed the validation of the hypothesis that in long-term periods, economic growth would be possible if environmental issues are addressed, as well, and rejected this statement for Caribbean and Latin countries. Zaman and Moemen [13] carried out an investigation to analyse the relation between utilization of renewable energies, fixed cropland, the technology of exporting, health issues and $\mathrm{CO}_{2}$ production in 14 selected countries in Latin and Caribbean countries. It was found out that fixed cropland and electricity production from fossil fuels have a negative effect and increase the amount of $\mathrm{CO}_{2}$ production, while utilization of renewable technologies and using high-level technologies lower the negative impacts on the environment. Hanif [14] analysed the impact of fossil fuel consumption, electricity generation, the amount of imported oil and urbanization on the energy-environment-economic nexus in Latin American countries (1990-2015). It was concluded from the findings that it is necessary for these countries to develop and apply renewable energy programs to increase the quality of their environment and also decrease their dependency on oil importing.

Evolutionary algorithms, as well as machine learning are considered as powerful tools in the modelling of different energy systems [15]. For instance, the group method of data handling and least squares support vector machine are applied to model several engineering systems by selecting appropriate input data for proposing precise models [16,17]. 
The major distinction that gives superiority to renewable energy is the lower amount of GHGs (greenhouse gases) emission in comparison to typical fossil fuels. Different techniques and equipment are employed in energy systems for electricity production or other possible energy conversion targets such as heating or cooling, etc. [18-23].

Geothermal, solar and wind are the most practical sources of renewable energies, which have been developed vastly in recent years [24-32]. These sources are utilized in various applications such as power production, proving heating loads, freshwater production systems, etc. [33-38]. The amount of GHGs emission can be reduced by either increasing the portion of renewable energies in the total energy consumption or by improving the operational efficiency of energy-conversion systems. Various investigations have concentrated on optimization and enhancement of energy-conversion systems to reach more desired operating statuses [39-41]. One of the powerful tools that is highly utilized in the modelling process of the energy-conversion systems is machine learning. A recent method based on machine learning was introduced, Least Squares Support Vector Machine (LSSVM), which has been vastly used in modelling of engineering systems [42-51].

Applicable and fit data are required to have an accurate model. In this investigation, the input of the designed model was fuel consumption (i.e., oil, natural gas, coal and possible renewable energy sources) of countries in South America and the GDP of each studied country in the period from 1990-2016. The amount of carbon dioxide emission in each year was defined as the output of the study. Here, all of the influential items that were considered by other researches are gathered in order to give an inclusive model. Moreover, the most highlighted novelty of this study is proposing a mathematical model to estimate the amount of carbon dioxide emission of different countries in the region of South America and Mexico. The precision of the introduced model is examined and evaluated by statistical methods including relative error and R2 (R-squared).

Furthermore, patents can provide visual information about the future of the technology and the amount of investment in a policy. Accumulated numbers of published patents by a country not only determine the industrial orientation, but also demonstrate the future program of that country in a specific domain. Therefore, the mentioned countries are investigated in terms of the published patents in the technologies for mitigating greenhouse gas emission. In this paper, all patents that have been published by Brazil, Chile, Argentina, Uruguay, Mexico, Peru and Venezuela are extracted and analysed. Finally, the top five published patents by the mentioned Latin countries for mitigating $\mathrm{CO}_{2}$ emission technology are indicated.

\section{Methodology}

Based on Ahmadi et al. [52,53], applying some non-population optimization methods such as Levenberg-Marquardt (LM) and Simplex Simulated Annealing Algorithm (M-SIMPSA) is not practical since these approaches are not able to handle the SVM techniques since the nonlinearity factor is high. Therefore, GA, which is a population-based optimization method, was employed in order to assess the two major factors of $\gamma$ and $\sigma^{2}$. In addition, a fitness function was used in the external optimization process, i.e., the Mean Squared Error (MSE) of estimated data. In order to specify the most optimum result of the fitness function, the optimization process was repeated several times. Here, the LSSVM machine learning technique was hybridized with GA, PSO, ICA and GAPSO to model an accurate estimation of $\mathrm{CO}_{2}$ production in Latin American countries. Each methodology is briefly discussed in the following.

\subsection{Least Squares Support Vector Machine}

Suykens and Vandewalle introduced LSSVM for the first time in 1999 and applied it to the primary kind of SVM, in order to specify the regression and function. Over-fitting issues were recognized as a challenging situation when dealing either with conventional SVM or feed-forward neural networks. Therefore, the LSSVM is proposed to surmount this specific barrier. Here, $\mathrm{Xi}$, Rew, and GDP were defined as the input values of the problem, and $\mathrm{Yi}$ was the objective output. The time series of $\mathrm{Xi}$ 
consisted of oil (million tons), gas (million tons oil equivalent) and coal (million tons oil equivalent). Rew and GDP were measured as million tons oil equivalent and in billion 2005 U.S. dollars, respectively. Overall, the LSSVM nonlinear function can be demonstrated as follows [54-59]:

$$
f(x)=w^{T} \phi(x)+b
$$

$f$ illustrates the relation between input variables and the objective function of $\mathrm{CO}_{2}$ production (million tons). Input variables were oil (million tons), gas (million tons oil equivalent), coal (million tons oil equivalent), $R_{e w}$ (million tons oil equivalent) and GDP (billion 2005 U.S. dollars). $w$ represents the weight vector (m-dimensional); $\phi$ maps $x$ into the characteristic vector (m-dimensional); and $b$ states the bias [54-56].

In order to minimize the topology, defining a fitting error function is necessary for solving the regression problem [45-50]:

$$
\min J(w, e)=\frac{1}{2} w^{T} w+\gamma \sum_{k=1}^{m} e_{k}^{2}
$$

However, a constraint should be noted as follows [45-50]:

$$
y_{k}=w^{T} \phi\left(x_{k}\right)+b+e_{k} k=1,2, \ldots, m
$$

In Equation (3), $y$ is defined as the margin variable and $e_{k}$ indicates the loose parameter of $x_{k}[55-59]$.

Employing the Lagrange multipliers $\alpha_{i}$ in order to change the previous limited problem to an unlimited problem is a strong and efficient tool to determine the optimization problems that are stated in Equation (2) [55-59]:

$$
L(w, b, e, \alpha)=J(w, e)-\sum_{k=1}^{m} \alpha_{i}\left\{w^{T} \phi\left(x_{k}\right)+b+e_{k}-Y_{k}\right\}
$$

As stated in the investigation of Karush-Kuhn-Tucker (KKT), considering the stated variables including $w, b, e$ and $\alpha$ and also performing the partial derivatives of Equation (4), the optimum condition can be expressed as follows [55-59]:

$$
\begin{aligned}
& w=\sum_{k=1}^{m} \alpha_{i} \phi\left(x_{k}\right) \\
& \sum_{k=1}^{m} \alpha_{i}=0 \\
& \alpha_{i}=\gamma e_{i} \\
& w^{T} \phi\left(x_{i}\right)+b+e_{i}-Y_{i}=0
\end{aligned}
$$

Therefore, the linear equations are specified as [55-59]:

$$
\left[\begin{array}{cc}
0 & -Y^{T} \\
Y & Z Z^{T}+1 / \gamma
\end{array}\right]\left[\begin{array}{l}
b \\
\alpha
\end{array}\right]=\left[\begin{array}{l}
0 \\
1
\end{array}\right]
$$

In Equation (5), $Y, Z, I$ and $\alpha$ are defined as: $\left\{Y=Y 1, \ldots, Y_{m}\right\}, Z=\phi\left(X_{1}\right)^{T} Y_{i}, \ldots, \phi\left(X_{m}\right)^{T} Y_{m}$, $I=[1, \ldots, 1]$ and $\alpha=\left[\alpha_{1}, \ldots, \alpha_{1}\right]$, respectively. By applying the kernel function of $K\left(X, X_{k}\right)=$ $\phi(X)^{T} \phi\left(X_{k}\right), i=1, \ldots, m$, the discussed LSSVM regression is formulated as follows [55-59]:

$$
f(x)=\sum_{k=1}^{N} \alpha_{k} K\left(x, x_{k}\right)+b
$$


The Radial Basis Function Kernel (RBFK) is typically utilized in regression errors. This function is stated as follows [55-59]:

$$
K\left(x, x_{k}\right)=\exp \left(-\frac{\left\|x_{k}-x\right\|^{2}}{\sigma^{2}}\right)
$$

In Equation (8), $\sigma^{2}$ indicates the squared bandwidth. This parameter should be calculated during any optimization procedure, such as the GA optimization method, in order to have a potent optimization approach. The Mean Squared Error (MSE) of the results of the LSSVM optimization approach is defined as the target function. The MSE of the results of the LSSVM method can be expressed as follows [60-67]:

$$
M S E=\frac{\sum_{i=1}^{n} \mathrm{CO} 2_{\text {rep } / \text { pred }_{i}}-\mathrm{CO} 2_{\text {meas }_{i}}}{n s}
$$

where $\mathrm{CO}_{2}$ illustrates the amount of $\mathrm{CO}_{2}$ emission (million tons) and subscripts rep/pred and meas denote predicted and measured amount of $\mathrm{CO}_{2}$ emission, respectively. The number of samples from the original population is indicated by ns. In this investigation, the evolved model of the LSSVM method, which was previously implemented by Pelckmans et al. [59] and Suykens and Vandewalle [60], was applied.

In general, Equation (10) simply states the optimization issue:

$$
\operatorname{Min} F\left(\gamma, \sigma^{2}\right)=\operatorname{Min}(M S E)
$$

\subsection{Evolutionary Algorithms}

\subsubsection{Genetic Algorithm}

The preliminary stage of the Genetic Algorithm (GA) procedure is to form the primary population. Then, every stage is precisely assessed to form a statistical fitness function. In the following, every stage should be evaluated to be compatible. The "global best satisfactory" result, which is the result with a range of acceptable error, ended the algorithm, and then, the parameters were extracted and reported. When the global best satisfactory result was not achieved, weaker individuals were opted to be deleted in the next stage. In the next stage, in order to decrease the error, mutation and cross-over operations were applied. This stage is then called the "evaluation fitness" [68-71]. The process of the genetic algorithm LSSVM is demonstrated in Figure 1.

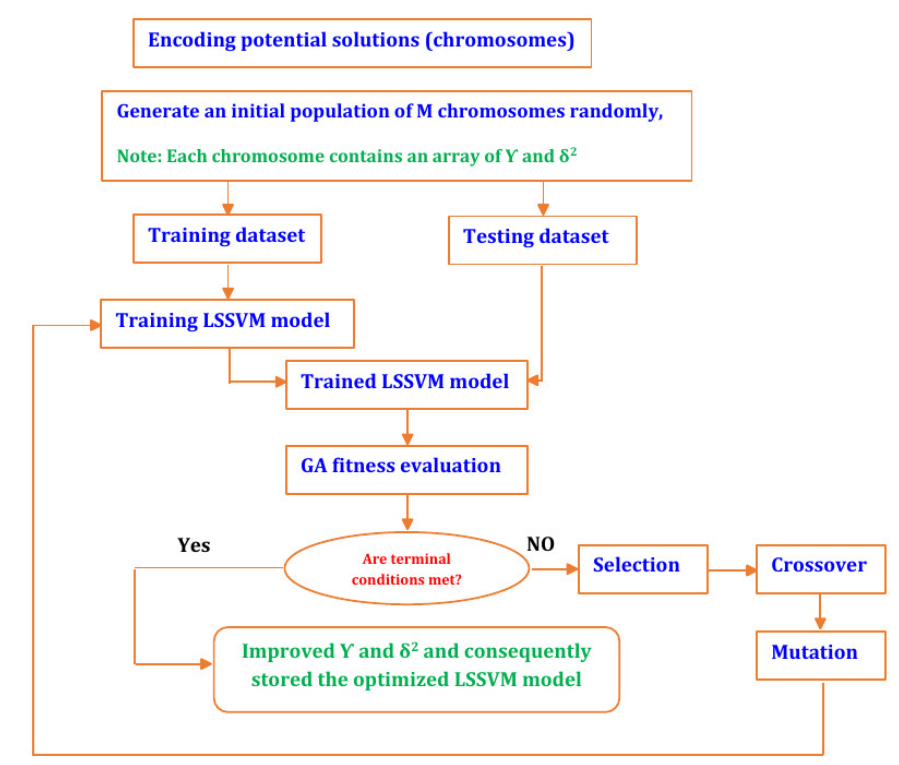

Figure 1. The overall scheme of the GA-least squares support vector machine method [72]. 


\subsubsection{Particle Swarm Optimization}

At the commencement of Particle Swarm Optimization (PSO), pattern arbitrary locations and velocities are used to initialize the primary population. The particle's fitness is then performed by utilizing the statistical function. The desired factors are extracted, when the particle's fitness rate meets the stopping norms. In the cases that the desired fitness rate is not achieved, in order to fulfil the requested rate, the particle's velocity and locations are varied under specific conditions. In the first step, the global best factor should be evaluated and used to monitor how the particle fitness is in comparison to the global best. An update to the pertinent factors of the prime particle is needed when the fitness is greater than the global paramount fitness. At last, subsequent particles should be assessed again by changing the direction to the 2nd stage [73-76]. The schematic process of the PSO-LSSVM is illustrated in Figure 2.

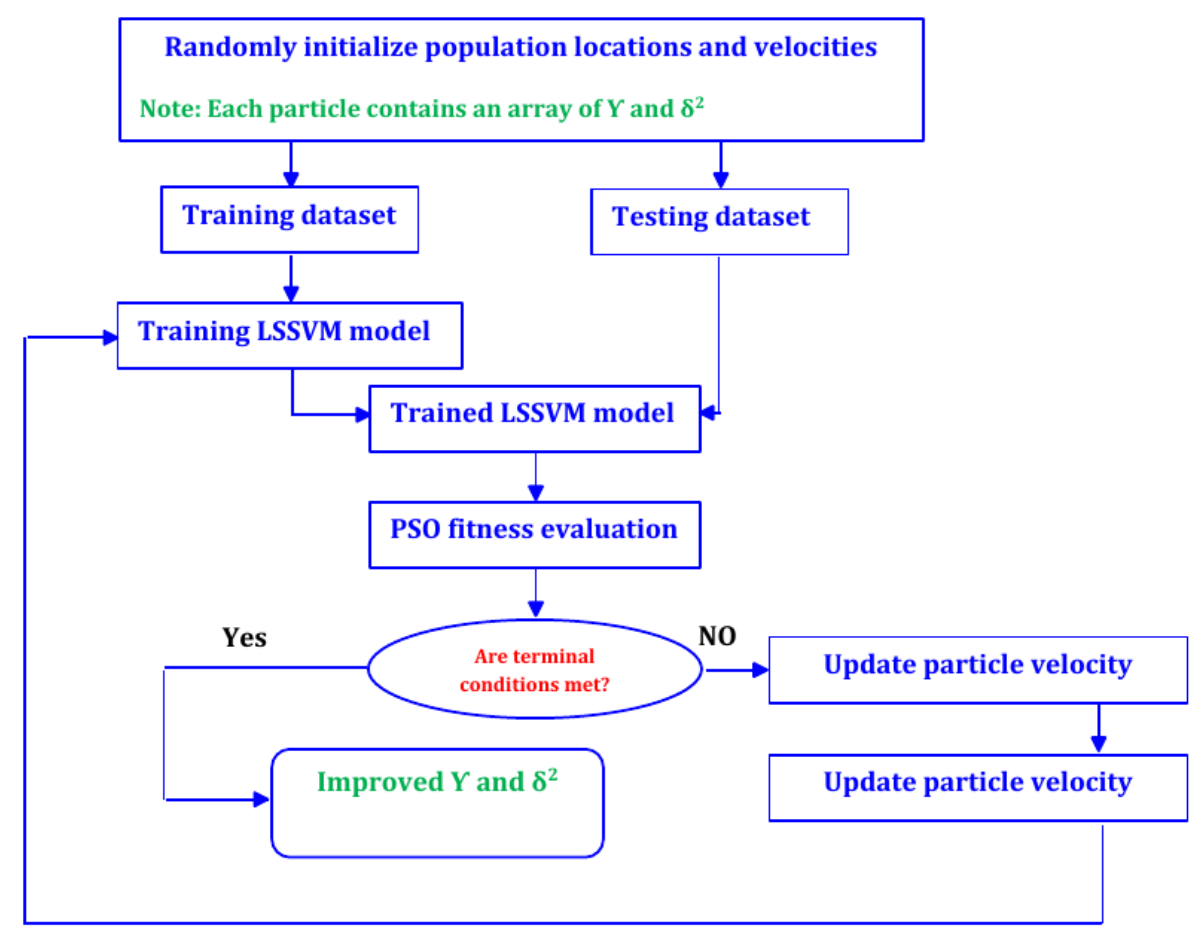

Figure 2. The overall scheme of the PSO-least squares support vector machine [72].

\subsubsection{Hybrid PSO and GA}

This hybridization is started by arbitrarily forming the primary population and its following assessment. The process is stopped when the regulated values of the amount of produced error of the best individual is achieved. If the regulated values are not met, then the procedure continues to reach toward the closest acceptable range by utilizing the PSO algorithm. In this algorithm, the number of leaders are increased, tournament selection is carried out based on the chaining processes, mutations and cross-over operations are applied and, finally, the fresh offspring are generated. New populations with improved characterizations of elites and offspring are generated by merging the effects of these two methods with each other $[77,78]$. The box chart of the Hybrid GAPSO-LSSVM method is shown in Figure 3. 


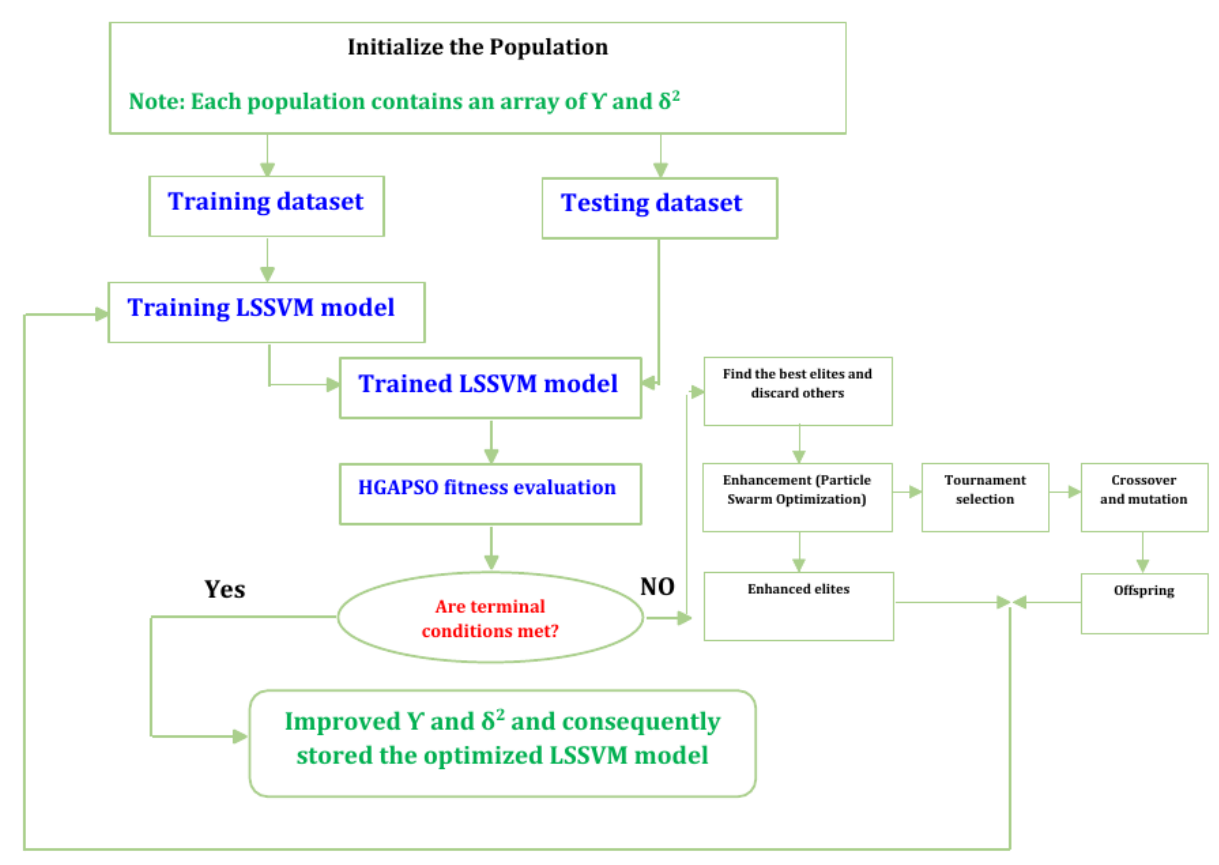

Figure 3. The overall scheme of the hybrid approach of PSOGA-least squares support vector machine method [72].

\subsubsection{Imperialist Competitive Algorithm}

Imperialist Competitive Algorithm (ICA) follows a similar process as GA to solve optimization problems. However, ICA is based on a human socio-political organization and evolution strategy instead of the biological evolution of GA. ICA creates several social domains, transferring a number of colonies to their related domains. Then, the colony's cost of an empire should be evaluated. A variation in the locations of domains and colonies is needed when the colony's cost is high for a specific domain. After that, the cost of all domains is computed in the next step. In the following phase, the greatest colony of the greatest domain owns the colony with the lowest potential. Afterwards, all domains without colonies should be cut. The next level is to examine the breaking sets to monitor the amount of satisfaction to cease the algorithm $[79,80]$. The schematic diagram of the ICA-LSSVM method is demonstrated in Figure 4.

The LSSVM Lab 1.8 free toolbox and GA Toolbox of MATLAB R2009a were used to optimize the GA-LSSVM problem. In addition, other optimization techniques including ICA, PSO and hyper-PSOGA were coded and run in MATLAB software in order to determine the hyperparameters of the LSSVM. When the dataset was identified and collected, the model was formed and the input parameters into the model and the target output of the model were specified. Based on the reported data from the mentioned literature, the amount of carbon dioxide emission (million tons) was selected as the output of the LSSVM model and forecasted.

The collected real data were classified into two subclasses: $80 \%$ of the total data, which was 68 data points or 55 data lines, were employed in the training process; the other $20 \%$ of the data established the test and validation process to verify the recommended method.

The RBF was opted for this problem, since there were few variables in this optimization problem and also the 1st-rate total performance of the RBF kernel function. Based on the literature, the RBF is in agreement with other kernel functions and also is highly practical [81,82]. In the process of modelling the problem utilizing the LSSVM with RBF kernel function, the feature of parameters $\gamma$ and $\sigma^{2}$ is a fundamental task (see Equation (8)). These parameters have a noticeable role in verifying the acceptance of the LSSVM approach used. Here, the regularization factor is indicated by $\gamma$, and $\sigma$ denotes the kernel sample variance [83] (see Figure 5). 


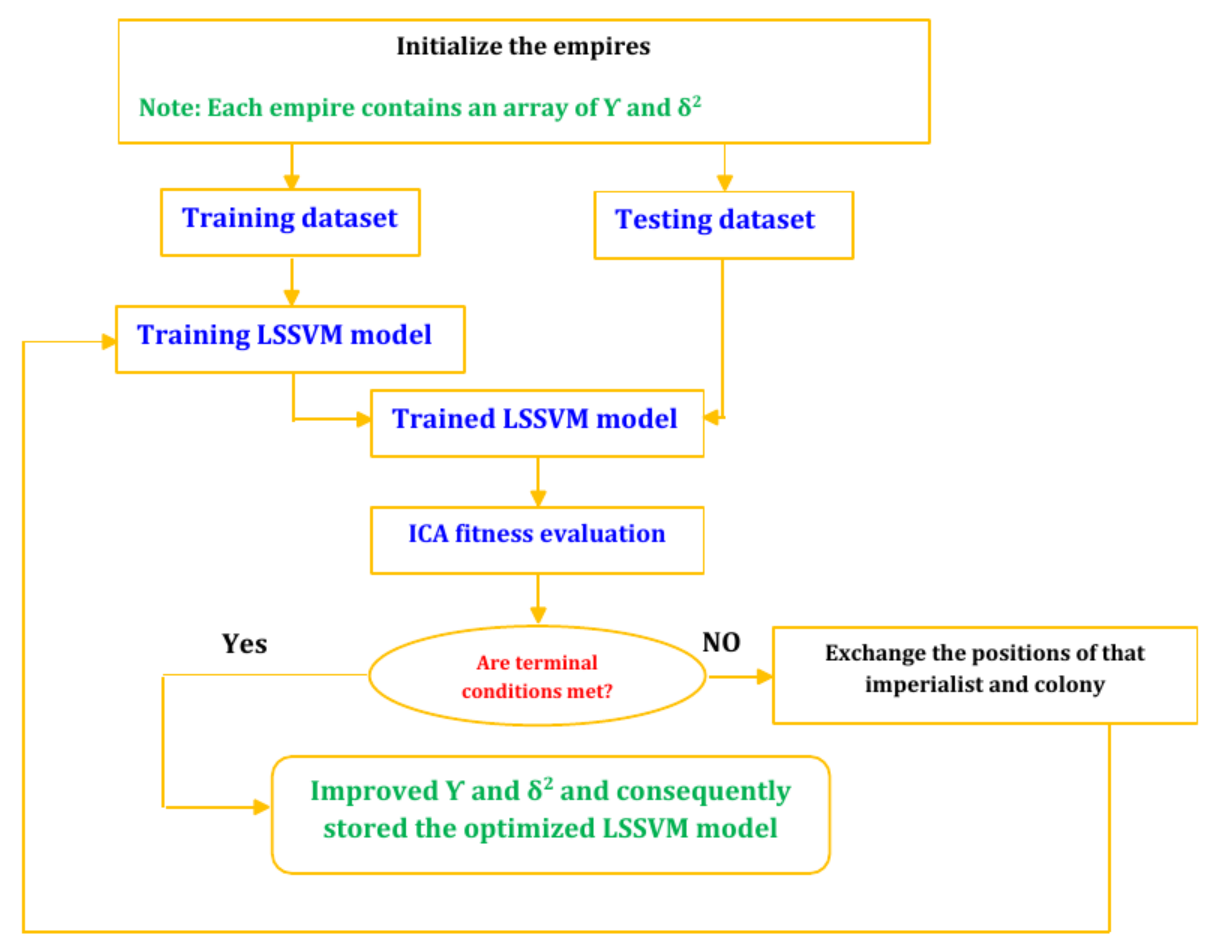

Figure 4. The overall scheme of the Imperialist Competitive Algorithm (ICA)-least squares support vector machine method [72].

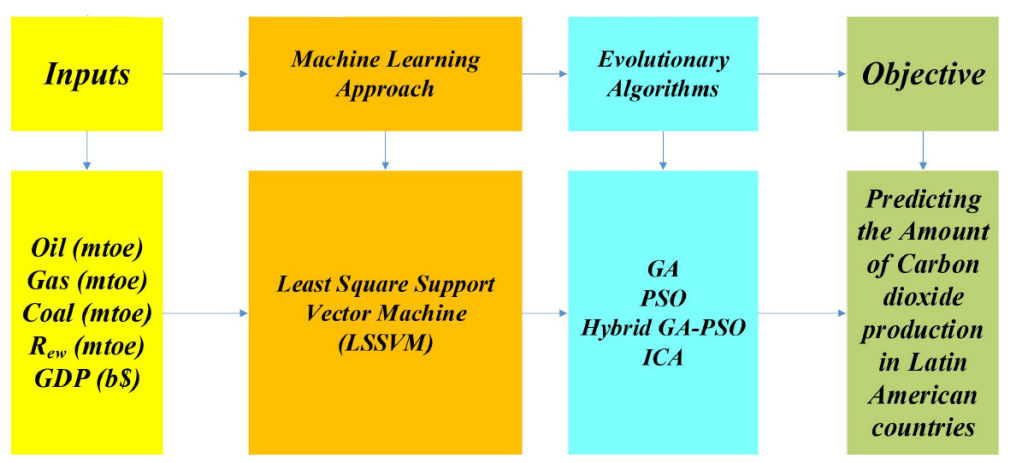

Figure 5. Schematic diagram of the employed methodology to predict the amount of produced carbon dioxide in Latin American countries (mtoe: million tons oil equivalent; b\$: billion dollars).

\section{Patent Analysis}

Is there any helpful technology for mitigating greenhouse gas emission? What are the technological roles of South American countries in mitigating greenhouse gas emission? One of the reliable approaches to denote the technological profile of countries is patent analysis. Patents have a technical value, determining the market potential $[84,85]$. The economics of a patent can be an indicator of the market tendency of that technology. The patent provides useful information for the business developer, policy makers and researchers. To extract this information and visualize it, analysing the patent is required [86]. Patent analysis, besides showing the technology trend, can demonstrate countries' orientation on the specific technology sector. The total published patents in the specific technology by a country may indicate is movement in that specific industry. Additionally, one of the interesting results of the analysis of the patent can be the indication of a hot area in technology. Indeed, the specific groups of technology used by a country are found by this analysis. 
Therefore, what are the technological approaches of these countries for mitigating $\mathrm{CO}_{2}$ emission? Have they matured in their technology? To estimate their technological approaches, investigating patents could be helpful. To find the technology status, the technological life cycle is curved. As was said earlier, patents were used as data for this investigation. Patents can be assumed as one of the most reliable indexes for estimating technology development. Patents, by stimulating the economy and technological innovation, motive firms to develop the technology $[79,81]$. Patents play a climatic role in highlightingbetter technology life cycles and each step through innovation, technology development to market growth [78]. The data were extracted from the SaaS online database, Patentispiration (Patentispiration.com). Finding the best approach for mitigating $\mathrm{CO}_{2}$ emission technologies that are employed by the mentioned countries was determined by investigating the obtained patents. Thus, the exactness of the extracted patent is the key factor of this investigation. Since searching patents by keywords may not be an efficient method, the combination of keywords and patent codes significantly increased the data accuracy. In the first place, interviewing of experts was done to refine the main keywords. Then, the patents were searched by keywords, which are shown in Figure 6. These keywords were candidate from the result of interviewing.

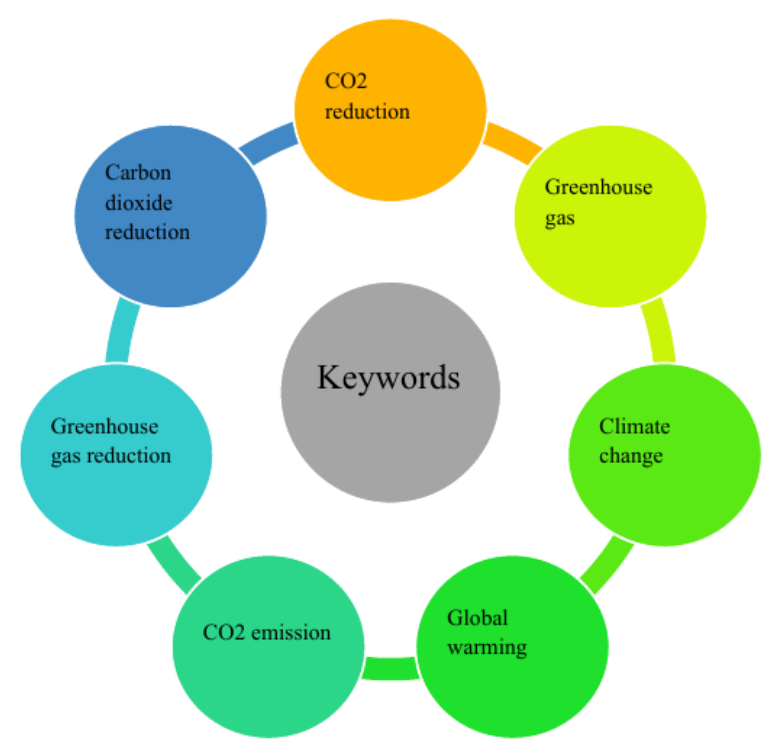

Figure 6. Related keywords for searching patents.

After searching by keywords, the extracted patents were screened to find key codes. Key codes refer to CPC (Cooperative Patent Classification), which organizes the patents into nine classes. Searching patents by codes averts extracting irrelevant patents; therefore, this approach certifies the accuracy. For better insight into the technology categories, the hierarchy of CPC of the patent survey is presented in Table 1.

Table 1. The hierarchy of the extracted patents on climate change mitigation technologies.

\begin{tabular}{cccl}
\hline Section & Class & Subclass & Definition \\
\hline & & Y02A & Technologies for adaptation to climate change \\
& & Y02B & Indexing scheme related to buildings \\
& Y02C & Capture, storage, sequestration or disposal of greenhouse gases \\
Y & Y02 & Y02D & Information and communication technologies \\
& & Y02E & Reduction of GHG emission related to energy generation and distribution \\
& & Y02P & Production or processing of goods \\
& Y02T & Transportation \\
& Y02W & Wastewater treatment or waste management \\
\hline
\end{tabular}


After finding key codes, the patents of Brazil, Argentina, Mexico, Peru, Venezuela, Chile and Uruguay were analysed. The extracted patent database covered 1970-2017.

\section{Results and Discussion}

The values of $\sigma^{2}$ and $\gamma$ for the studied methods including GA, PSO, ICA and hybrid GAPSO were obtained and are listed in Table 2. In addition, sensitivity analysis was performed on the numbers of the introduced digits of the mentioned variables.

Table 2. The hierarchy of extracted patents on climate change mitigation technologies.

\begin{tabular}{lcc}
\hline & $\sigma^{2}$ & $\gamma$ \\
\hline Genetic Algorithm (GA) & 5.32 & $51,088.13$ \\
Particle Swarm Optimization (PSO) & 5.3178 & $51,037.11$ \\
Imperialist Competitive Algorithm (ICA) & 5.3069 & $50,099.84$ \\
Hybrid GAPSO (HGAPSO) & 5.3296 & $52,039.38$ \\
\hline
\end{tabular}

The predicted obtained values through the GA-LSSVM model in comparison to the real amount of measured carbon dioxide emission for South America is depicted in Figure 7a. In order to obtain the best linear fit line between the predicted and real amount of $\mathrm{CO}_{2}$ emission, a correlation coefficient of 0.9965 resulted in the GA-LSSVM. The closeness of the coefficient to the unit demonstrates that the forecasted and measured data points were similar. The scatter plot of the amount of forecasted $\mathrm{CO}_{2}$ emission through PSO-LSSVM vs. the measured data is illustrated in Figure 7b. Applying the PSO-LSSVM method resulted in the correlation coefficient of 0.9957 for the best linear fit line between the predicted and measured values of $\mathrm{CO}_{2}$ emission. It can be seen than the calculated correlation coefficient was closer to unity in PSO-LSSVM than the GA-LSSVM method, and it can be stated that the precision of PSO-LSSVM model was higher and the estimations close enough to the measurements of the carbon dioxide emission. The regression plot of the obtained results from the HGAPSO-LSSVM method and related actual amount of carbon dioxide emission is demonstrated in Figure 7c. The regression of the predicted results through the ICA-LSSVM model in comparison to actual measured data of the carbon dioxide emissions is depicted in Figure $7 \mathrm{~d}$. As can be clearly understood, based on the values of the correlation coefficient, the ICA-LSSVM approach gained the lowest amount among all other models, including PSO-LSSVM, GA-LSSVM and HGAPSO-LSSVM.

It was concluded that among all the discussed methods, the HGAPSO-LSSVM technique was more accurate based on the obtained correlation coefficients. In addition, the relative deviation of the calculated results through the discussed methods vs. corresponding oil production (million tons) is demonstrated in Figure 8. It can be seen from Figure 8a that the obtained results from the GA-LSSVM model deviated from actual measured carbon dioxide emission values by $20 \%$. This means that the deviation of the obtained results by the GA-LSSVM model from the real measured amount of carbon dioxide was about $15 \%$. It can be understood from Figure $8 \mathrm{~b}$ that the deviation of the obtained results through the PSO-LSSVM model was in the range of $22 \%$. It can be stated that the error of estimations from the PSO-LSSVM model was between the error lines of $-22 \%$ and $+22 \%$. The relative error graph of the estimations based on the HGAPSO-LSSVM model in comparison to the actual measured data to carbon dioxide emission is depicted in Figure 8c. It can be clearly seen from Figure $8 \mathrm{c}$ that the highest error of the HGAPSO-LSSVM model was in the range of $12 \%$. The relative deviation results of ICA-LSSVM model are shown in Figure 8d. It can be seen from Figure 8d that the highest deviation of the ICA-LSSVM approach from actual $\mathrm{CO}_{2}$ emission was $-22 \%$. The relative error distribution shows that the HGAPSO-LSSVM method had dominance in comparison to the other discussed LSSVM models. Overall, two dependable statistical benchmarks including Average Absolute Relative Deviation (AARD\%) and MSE were applied to determine powerful intelligent techniques among the recommended LSSVM models. 


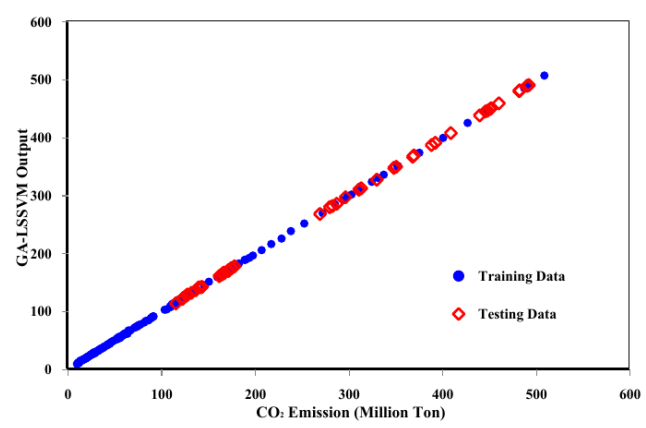

(a) Estimated values obtained from the GA-LSSVM approach vs. actual measured values of $\mathrm{CO}_{2}$ emission

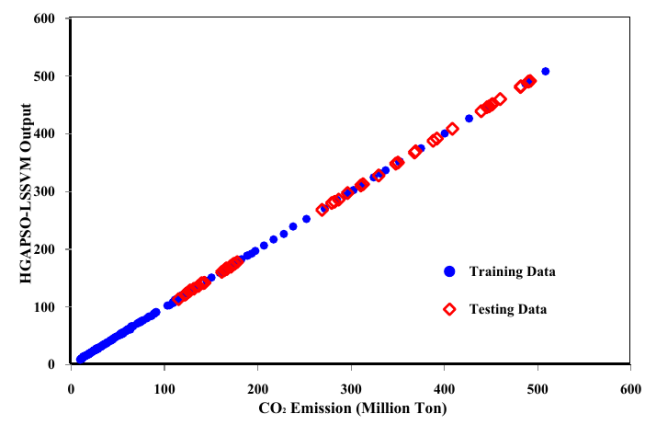

(c) Estimations based on the HGAPSO-LSSVM model vs. actual $\mathrm{CO}_{2}$ emission

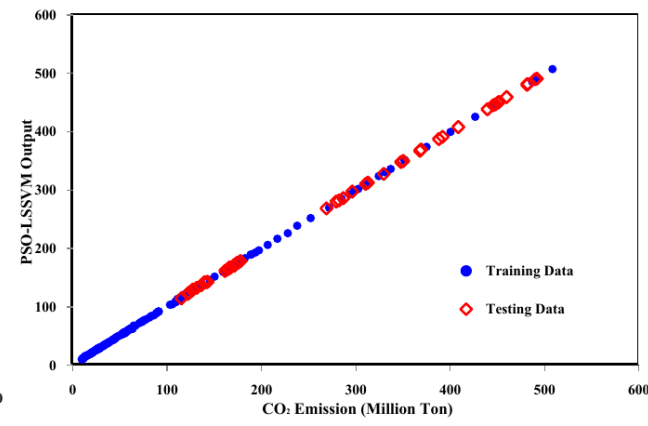

(b) Output of the PSO-LSSVM model vs. actual measured data of $\mathrm{CO}_{2}$ emission

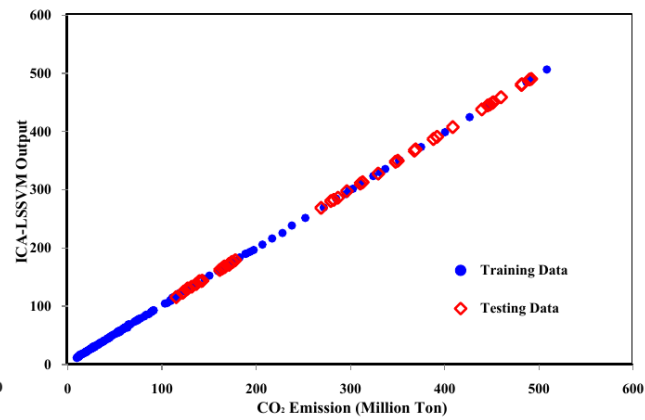

(d) Prediction based on the ICA-LSSVM technique vs. actual measured $\mathrm{CO}_{2}$ emission

Figure 7. Model comparison.

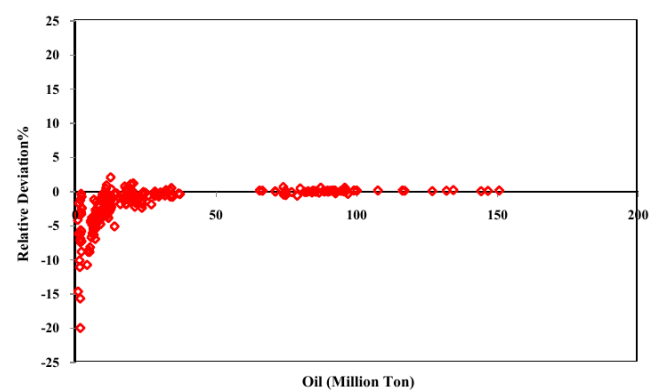

(a) Relative error of the estimations based on GA-LSSVM

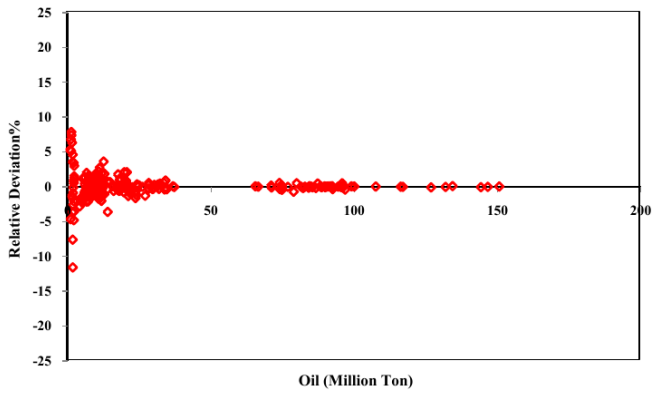

(c) Relative error of the estimations based on HGAPSO-LSSVM

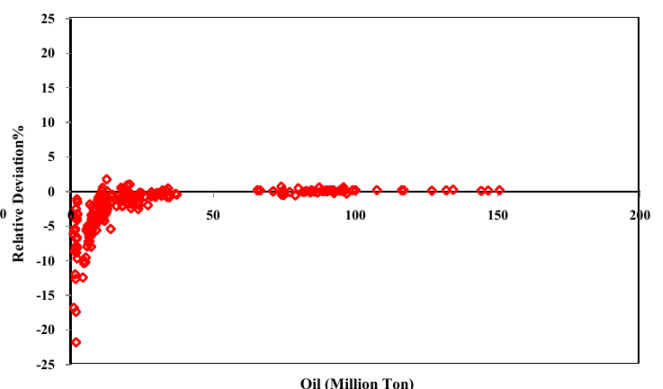

(b) Relative error of the estimations based on PSO-LSSVM

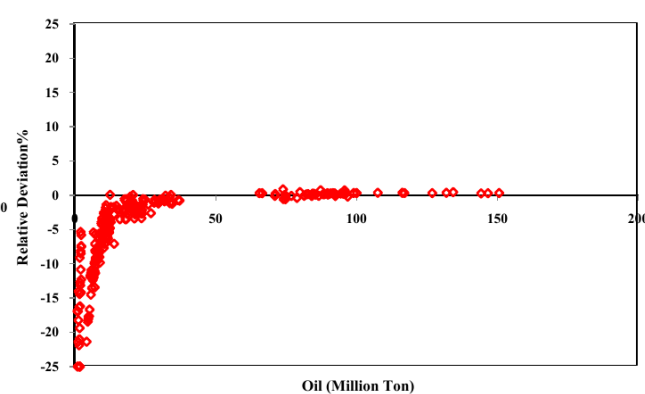

(d) Relative error of estimations based on ICA-LSSVM

Figure 8. Relative error per model. 
The obtained AARD (\%) from the LSSVM methods and the actual logged data of carbon dioxide emissions are compared and demonstrated in Figure 9a. In addition, Figure $9 \mathrm{~b}$ depicts the comparison between the resulting MSE of different LSSVM models. It can be seen from Figure 9 that the HGAPSO-LSSVM technique is an accurate and precise method for estimating $\mathrm{CO}_{2}$ emission in gas injection processes.

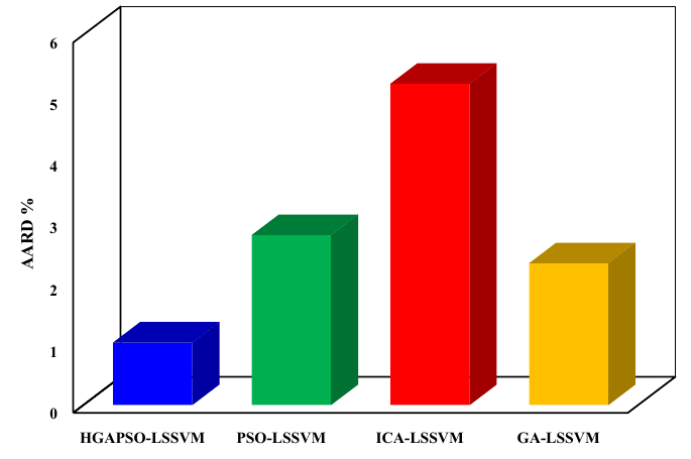

(a) Average Absolute Relative Deviation (AARD) of the studied LSSVM approaches

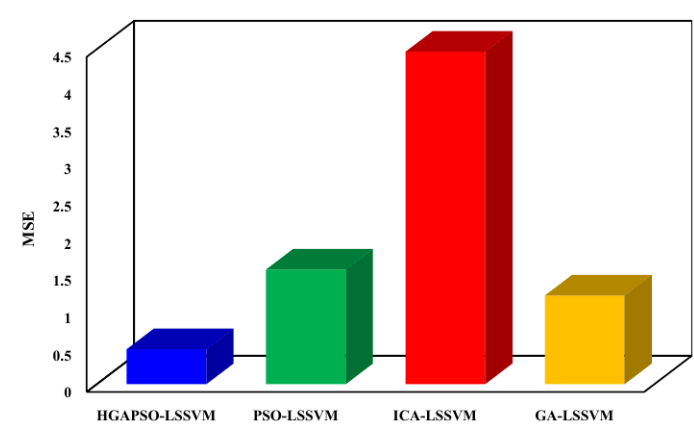

(b) Mean Squared Error (MSE) of the studied LSSVM approaches

Figure 9. Errors for the LSSVM-based models.

The obtained programming codes and the required instructions are straightforwardly accessible and will be shared readily with others. Therefore, people can easily use the model to re-calculate all of our results and may predict carbon dioxide emission for any circumstances.

The patent analysis result of the technology trend for mitigation of $\mathrm{CO}_{2}$ shows that Brazil with 5885 patents is the leader in mitigation of $\mathrm{CO}_{2}$ emission technology so far. All the published patents of the South American countries are illustrated in Figure 10.

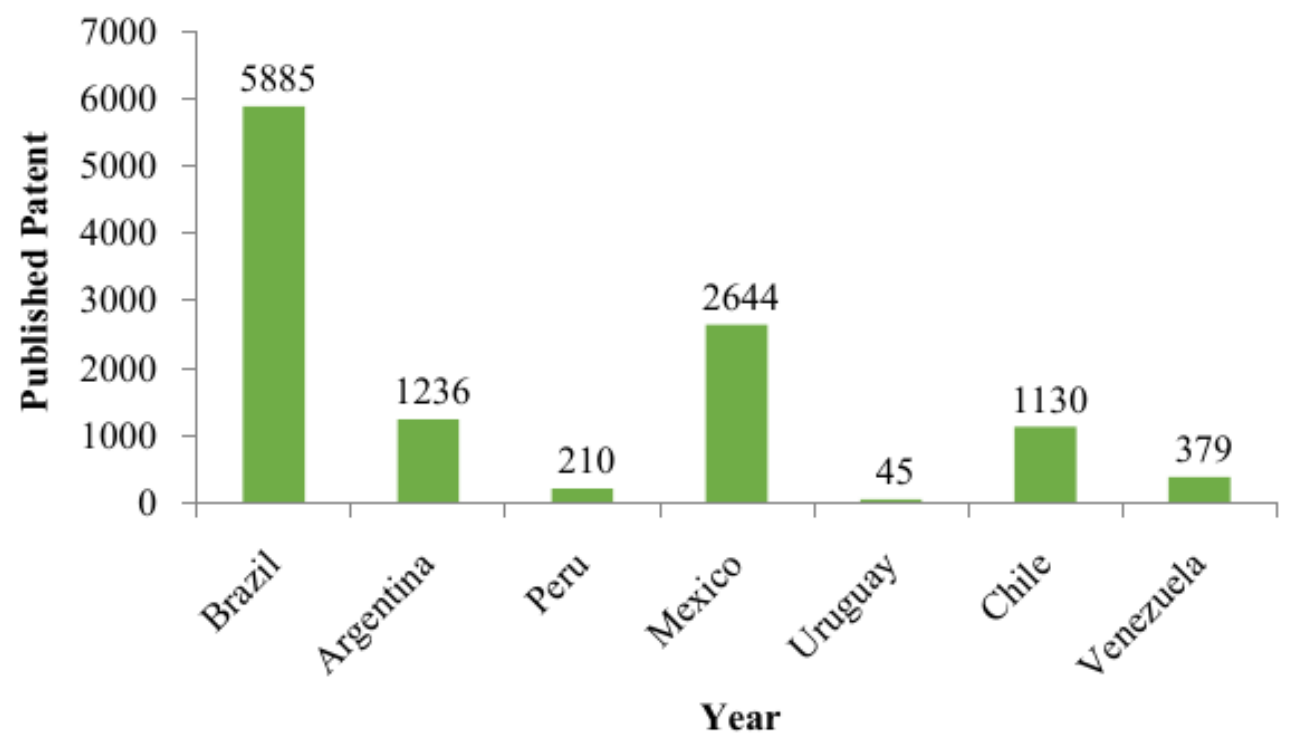

Figure 10. The number of published patents in South American countries.

Mexico has published 2644 patents and after Brazil is the second pioneer country. According to the extracted data, which were patents in this case, only 101 patents have been published by Uruguay. The trends of published patents by these countries from 2007-2017 are illustrated in Figure 11. What can be noted in the countries' trends is that Chile and Peru have accelerated working on mitigating 
technologies. The top patent main technology groups that indicate movement of these countries to mitigate $\mathrm{CO}_{2}$ emission will be discussed further. The country with a modest behaviour would be Venezuela. Furthermore, Mexico can be considered as the next most modest country in published patents. In fact, the published patents by country in the specific technology determines R\&D activities and expenditure directed toward mitigating $\mathrm{CO}_{2}$ emission.

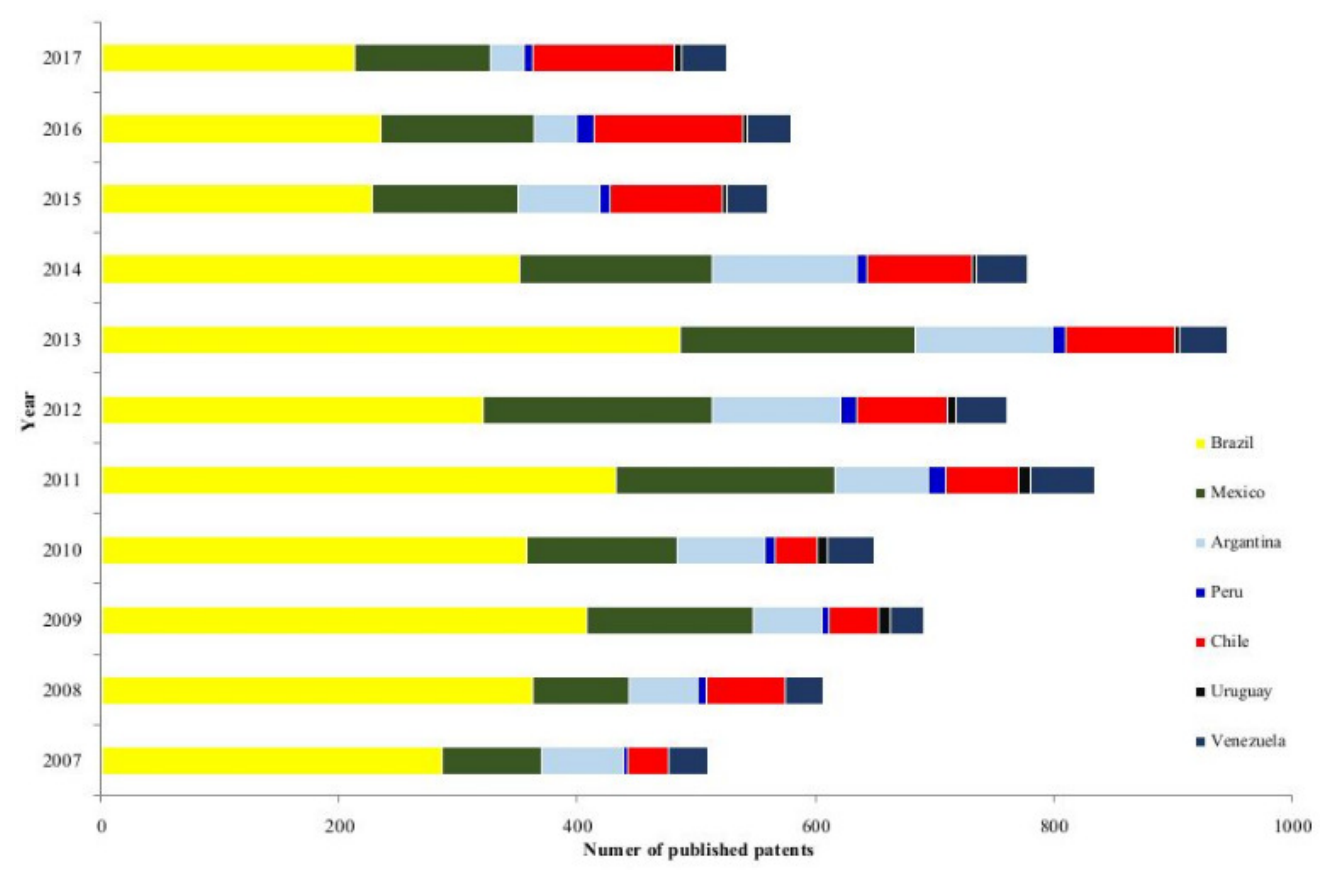

Figure 11. South American countries' activity in the recent decade.

Brazil and Mexico have the biggest economies in Latin America, which determines their remarkable role in $\mathrm{CO}_{2}$ mitigation. Although the $\mathrm{CO}_{2}$ emission from Brazil and Mexico is not the highest one, their policy and program to enhance mitigation action are considered globally [87]. Argentina has the fourth biggest economy in Latin America. In spite of being a relatively small $\mathrm{CO}_{2}$ emitter, Argentina has made efforts to mitigate $\mathrm{CO}_{2}$ emission recently. Peru is one of the countries that ratified the Paris agreement. The annual rate of $\mathrm{CO}_{2}$ emission of Peru in 2016 was 2.67\%, which determines 0.68 metric tons $\mathrm{CO}_{2}$, increasing from 1997-2016 [88]. As is obvious in Figure 11, Uruguay patent trends have not increased or faced a considerable change during the last decade. About $80 \%$ of $\mathrm{CO}_{2}$ in Uruguay was produced by the agriculture sector in 2013 [89]. According to its GDP, Venezuela has the seventh largest economy in Latin America. The main source of $\mathrm{CO}_{2}$ emission is energy in Venezuela. The total produced $\mathrm{CO}_{2}$ by Venezuela in 2014 was 6.03 metric tons [89]. Chile is another important Latin American country with a high GDP. The total $\mathrm{CO}_{2}$ emission by Chile in 2016 was 5.45 metric tons [90]. To find out the technological orientation of the mentioned Latin countries, the main technology groups of each country's patents are illustrated by Figure 12, which considers the technologies for mitigating $\mathrm{CO}_{2}$ emission published as patents by the mentioned Latin American countries, except Uruguay. The reason for considering Uruguay as an exception is the low number of patents. Only 45 patents have been published by this country, which demonstrates that the major activity by Uruguay is to promote renewable energies. Being a developing country and less industrialized, and not significant, does Uruguay have an influence on $\mathrm{CO}_{2}$ emission? However, the approach of Uruguay to reduce $\mathrm{CO}_{2}$ is promoting renewable energies. The energy sector in Uruguay contributed more than $90 \%$ of $\mathrm{CO}_{2}$ emissions, and the ambition is to reduce this by $29 \%$ by 2025 [91]. 


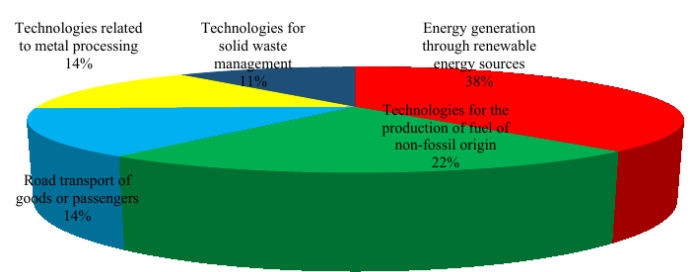

(a) Brazil

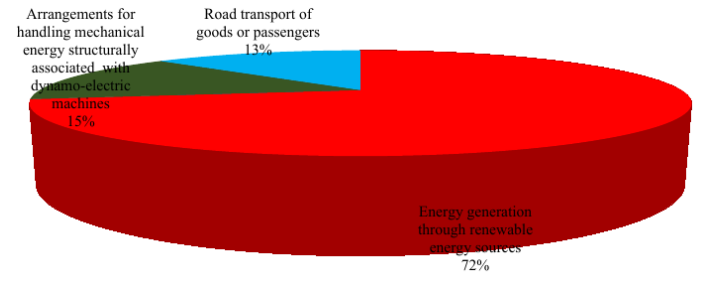

(c) Argentina

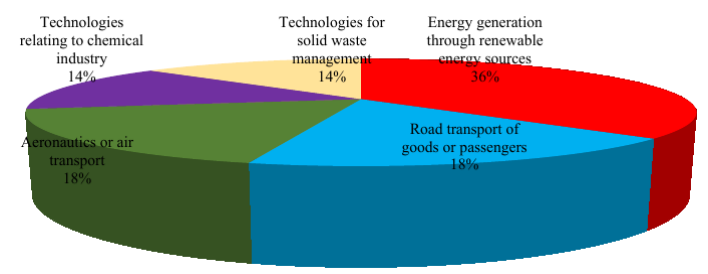

(e) Peru

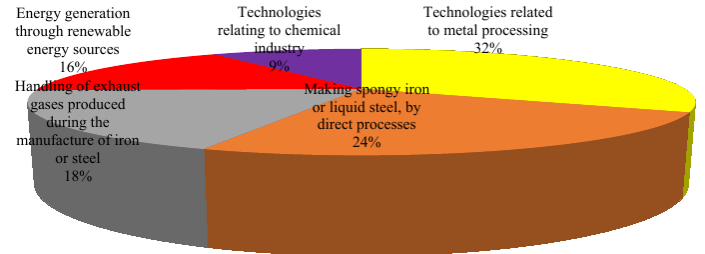

(b) Mexico

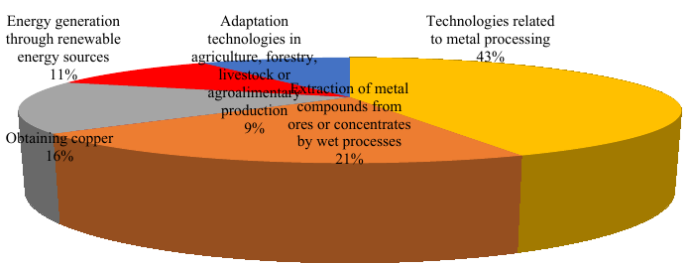

(d) Chile

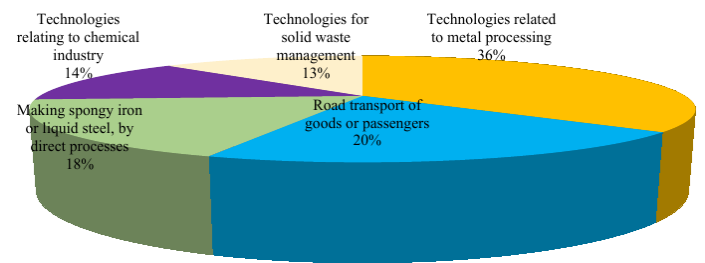

(f) Venezuela

Figure 12. Top five published patents by country in mitigating $\mathrm{CO}_{2}$ emission technology.

Figure 12a demonstrates the top five patent technology scopes that have been published by Brazil since 1970. Energy generation through renewable energy resources and technologies for the production of fuel of non-fossil origin, which is $60 \%$, is the lion's share of technologies for mitigation of $\mathrm{CO}_{2}$ emission. Production of fuel from non-fossil fuel origin includes biofuel technologies. One of the programs for achieving 10\% reduction of greenhouse gasses by 2028 is Brazil's biofuel mix stimulation from the current $20 \%$ to $28.6 \%$ [92]. In fact, Brazil's key strategies include a deforestation action plan and developing renewable energies. The other approach in order to reduce $\mathrm{CO}_{2}$ emission involves the industrial sector: modifying the efficiency of processes [93]. Mexico as the second biggest economy in the region, besides developing a renewable energies program, concentrates more on specific regulatory tools in the industrial sector. As is obvious in Figure 12b, only 13\% of the top five technologies are allocated to energy generation through renewable energy resources. Mexico is the thirteenth largest steel producer in the world, which produces more than $14 \% \mathrm{CO}_{2}$ [94]. For that reason, the four other areas of technologies in which more efforts are made in the $\mathrm{R} \& \mathrm{D}$ activities are the metal and related chemical industries. Therefore, the main program for mitigation of $\mathrm{CO}_{2}$ emission in Mexico would be improving the energy efficiency. Regarding Figure 12c, which demonstrates the technology sector in Argentina with respect to published patents, energy generation through renewable energy resources accounts for more than $70 \%$ of the patents. Road transport of goods or passengers and arrangements for handling mechanical energy structurally associated with dynamo-electric machines are the next highlighted ones. Their target that the net emissions must not exceed more than $483 \mathrm{MtCO}$ eq is divided into three main sectors, which are energy, forest and transport. The main scenario for Argentina to mitigate $\mathrm{CO}_{2}$ is renewable energies' promotion [95]. Indeed, developing renewable energies has gained the majority of funds in Argentina through the renewable energy auction program of Argentina (RenovAr). As a result of the first round of this program, the total wind and solar capacities are $3469 \mathrm{MW}$ and $2813 \mathrm{MW}$, respectively [96]. The top five patent technologies that have been published by Chile from 1970-2017 are illustrated in Figure 12d. Being the world's largest exporter of copper [97], 
the main published sector of technology by Chile is the industrial sector. Although expanding the renewable capacity and transition from coal to non-conventional resources for energy supply comprise the main action plan of Chile in order to reduce $\mathrm{CO}_{2}$ emission, enhancing the efficiency of industrial processes has received high attention in their R\&D activities. Regarding Figure 12e, Peru's technology sectors for published patents are somewhat similar to Brazil. The energy generation through renewable energy sources accounts for $36 \%$, while the four other sectors have the same shares when combined into two groups. Forestry, energy and agriculture are the three main greenhouse gas sources in Peru. The main energy sources in Peru for electricity and transportation are gas power plants and imported oil and gasoline. Renewable energy can be the best opportunity for addressing electricity demand, and the transportation sector demands can be met by low-carbon technologies [98]. The auction plan for developing renewable energies by Peru is illustrated in Figure 13.

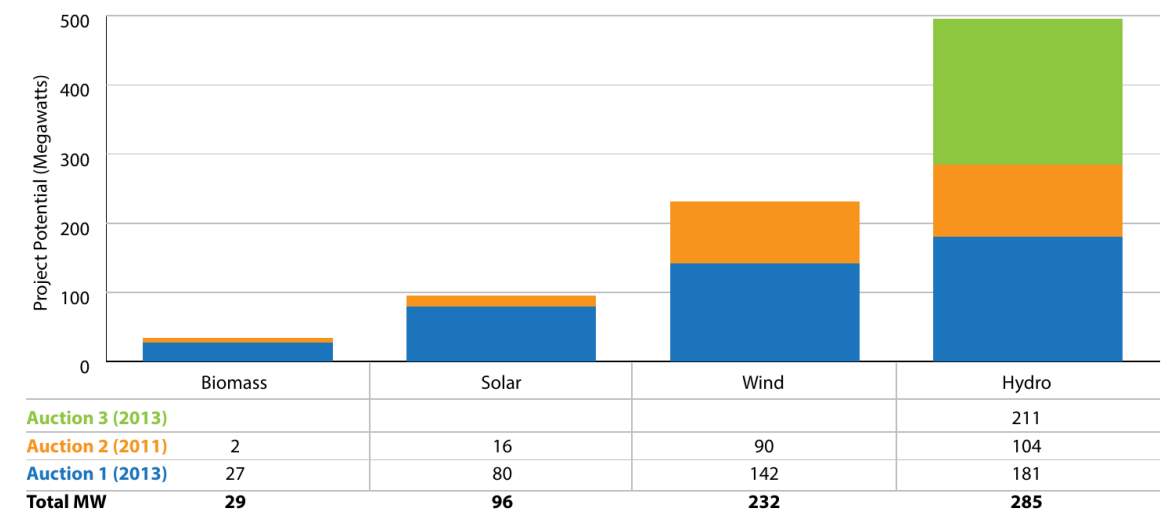

Figure 13. Renewable energies auction in Peru [98].

Despite other mentioned Latin American countries, in the top five published patents technology sectors, there is no share of energy generation through renewable energy sources in Venezuela in the published patents. The lion's share of the technology sector in the published patents by Venezuela is technologies related to metal processing, which account for $36 \%$, according to Figure $12 \mathrm{f}$.

\section{Conclusions}

In this investigation, two artificial intelligence techniques were discussed to estimate the $\mathrm{CO}_{2}$ emission. The LSSVM and evolutionary methods have been used to predict the $\mathrm{CO}_{2}$ emission precisely. The information used here was gathered from the accessible data in the literature. A comparison was made between the estimated amounts of $\mathrm{CO}_{2}$ from the optimization techniques and the measured actual data of carbon dioxide emission. Based on the recommended methods, the following major conclusions have been extracted:

1. All of the discussed optimization approaches showed agreement for forecasting the amount of carbon dioxide emission. However, HGAPSO-LSSVM demonstrated a more accurate result and showed a higher reliability and compatibility. In addition, under specific circumstances with restricted field information, the significance of these methods was highlighted more than other predicting techniques.

2. The HGAPSO has the potential to be integrated with other evolutionary algorithms in order to optimize its parameters and additionally enhance its strength and accuracy.

Moreover, the patents related to climate change mitigation were evaluated in six Latin American countries, namely Brazil, Mexico, Argentina, Peru, Chile, Venezuela and Uruguay. The results showed that, except Venezuela, all other mentioned countries have invested in renewable energy R\&D activities. Brazil and Argentina have the highest share of renewable energy, which accounts for $60 \%$ and $72 \%$, respectively. 
Author Contributions: All authors contributed equally to the paper.

Funding: This research received no external funding.

Conflicts of Interest: The authors declare no conflict of interest. The funding sponsors had no role in the design of the study; in the collection, analyses, or interpretation of data; in the writing of the manuscript; nor in the decision to publish the results.

\section{References}

1. Shirmohammadi, R.; Soltanieh, M.; Romeo, L.M. Thermoeconomic analysis and optimization of post-combustion $\mathrm{CO}_{2}$ recovery unit utilizing absorption refrigeration system for a natural-gas-fired power plant. Environ. Prog. Sustain. Energy 2018, 37, 1075-1084. [CrossRef]

2. Bistline, J.E.; Rai, V. The role of carbon capture technologies in greenhouse gas emissions-reduction models: A parametric study for the US power sector. Energy Policy 2010, 38, 1177-1191. [CrossRef]

3. Bowen, F. Carbon capture and storage as a corporate technology strategy challenge. Energy Policy 2011, 39, 2256-2264. [CrossRef]

4. Rai, V.; Victor, D.G.; Thurber, M.C. Carbon capture and storage at scale: Lessons from the growth of analogous energy technologies. Energy Policy 2010, 38, 4089-4098. [CrossRef]

5. Mathiesen, B.V.; Lund, H.; Karlsson, K. 100\% Renewable energy systems, climate mitigation and economic growth. Appl. Energy 2011, 88, 488-501. [CrossRef]

6. Romeo, L.M.; Calvo, E.; Valero, A.; De Vita, A. Electricity consumption and $\mathrm{CO}_{2}$ capture potential in Spain. Energy 2009, 34, 1341-1350. [CrossRef]

7. Landi, D.; Consolini, A.; Germani, M.; Favi, C. Comparative life cycle assessment of electric and gas ovens in the Italian context: An environmental and technical evaluation. J. Clean. Prod. 2019, 221, 189-201. [CrossRef]

8. Hdom, H.A. Examining carbon dioxide emissions, fossil \& renewable electricity generation and economic growth: Evidence from a panel of South American countries. Renew. Energy 2019, 139, 186-197.

9. Mardones, C.; Baeza, N. Economic and environmental effects of a $\mathrm{CO}_{2}$ tax in Latin American countries. Energy Policy 2018, 114, 262-273. [CrossRef]

10. Ozturk, I. Measuring the impact of alternative and nuclear energy consumption, carbon dioxide emissions and oil rents on specific growth factors in the panel of Latin American countries. Prog. Nucl. Energy 2017, 100, 71-81. [CrossRef]

11. Ruiz-Mendoza, B.J.; Sheinbaum-Pardo, C. Electricity sector reforms in four Latin-American countries and their impact on carbon dioxide emissions and renewable energy. Energy Policy 2010, 38, 6755-6766. [CrossRef]

12. Jardón, A.; Kuik, O.; Tol, R.S. Economic growth and carbon dioxide emissions: An analysis of Latin America and the Caribbean. Atmósfera 2017, 30, 87-100. [CrossRef]

13. Zaman, K.; Abd-el Moemen, M. The influence of electricity production, permanent cropland, high technology exports, and health expenditures on air pollution in Latin America and the Caribbean Countries. Renew. Sustain. Energy Rev. 2017, 76, 1004-1010. [CrossRef]

14. Hanif, I. Economics-energy-environment nexus in Latin America and the Caribbean. Energy 2017, 141, 170-178. [CrossRef]

15. Aslani, A.; Antila, E.; Wong, K.F.V. Comparative analysis of energy security in the Nordic countries: The role of renewable energy resources in diversification. J. Renew. Sustain. Energy 2012, 4, 062701. [CrossRef]

16. Ardakani, S.R.; Hossein, S.M.; Aslani, A. Statistical Approaches to Forecasting Domestic Energy Consumption and Assessing Determinants: The Case of Nordic Countries. Strateg. Plan. Energy Environ. 2018, 38, $26-71$. [CrossRef]

17. Aslani, A.; Hamlehdar, M.; Saeedi, R. Robustness of Norway Economy and Energy Supply/Demand. Int. J. Green Comput. (IJGC) 2017, 8, 1-19. [CrossRef]

18. Ahmadi, M.H.; Sayyaadi, H.; Dehghani, S.; Hosseinzade, H. Designing a solar powered Stirling heat engine based on multiple criteria: Maximized thermal efficiency and power. Energy Convers. Manag. 2013, 75, 282-291. [CrossRef]

19. Ahmadi, M.H.; Sayyaadi, H.; Mohammadi, A.H.; Barranco-Jimenez, M.A. Thermo-economic multi-objective optimization of solar dish-Stirling engine by implementing evolutionary algorithm. Energy Convers. Manag. 2013, 73, 370-380. [CrossRef] 
20. Ahmadi, M.H.; Mohammadi, A.H.; Dehghani, S.; Barranco-Jimenez, M.A. Multi-objective thermodynamic-based optimization of output power of Solar Dish-Stirling engine by implementing an evolutionary algorithm. Energy Convers. Manag. 2013, 75, 438-445. [CrossRef]

21. Maleki, A.; Pourfayaz, F.; Ahmadi, M.H. Design of a cost-effective wind/photovoltaic/hydrogen energy system for supplying a desalination unit by a heuristic approach. Sol. Energy 2016, 139, 666-675. [CrossRef]

22. Luo, X.; Wang, J.; Dooner, M.; Clarke, J. Overview of current development in electrical energy storage technologies and the application potential in power system operation. Appl. Energy 2015, 137, 511-536. [CrossRef]

23. Chu, S.; Cui, Y.; Liu, N. The path towards sustainable energy. Nat. Mater. 2017, 16, 16-22. [CrossRef] [PubMed]

24. Wang, C.; Zhang, S.; Yan, W.; Wang, R.; Liu, J.; Wang, Y. Evaluating renewable natural resources flow and net primary productivity with a GIS-Emergy approach: A case study of Hokkaido, Japan. Sci. Rep. 2016, 6, 37552. [CrossRef] [PubMed]

25. Jensen, T.V.; Pinson, P. RE-Europe, a large-scale dataset for modelling a highly renewable European electricity system. Sci. Data 2017, 4, 170175. [CrossRef]

26. King, L.C.; Van Den Bergh, J.C. Implications of net energy-return-on-investment for a low-carbon energy transition. Nat. Energy 2018, 3, 334-340. [CrossRef]

27. Carley, S.; Davies, L.L.; Spence, D.B.; Zirogiannis, N. Empirical evaluation of the stringency and design of renewable portfolio standards. Development 2018, 8, 13. [CrossRef]

28. Ksentini, A.; Bensalem, A.; Azzag, E.B. Management and technical economic analysis of a hybrid system (wind/diesel) in Southern Algeria. Int. J. Energy Technol. Policy 2016, 12, 60-83. [CrossRef]

29. Rau, G.H.; Willauer, H.D.; Ren, Z.J. The global potential for converting renewable electricity to negative- $\mathrm{CO}_{2}$-emissions hydrogen. Nat. Clim. Chang. 2018, 8, 621-625. [CrossRef]

30. Jacobson, M.Z.; Delucchi, M.A. SuStAinABle energy. Scientific American, November 2009.

31. Markard, J. The next phase of the energy transition and its implications for research and policy. Nat. Energy 2018, 3, 628-633. [CrossRef]

32. Naseri, A.; Bidi, M.; Ahmadi, M.H. Thermodynamic and exergy analysis of a hydrogen and permeate water production process by a solar-driven transcritical $\mathrm{CO}_{2}$ power cycle with liquefied natural gas heat sink. Renew. Energy 2017, 113, 1215-1228. [CrossRef]

33. Nazari, M.A.; Ahmadi, M.H.; Ghasempour, R.; Shafii, M.B.; Mahian, O.; Kalogirou, S.; Wongwises, S. A review on pulsating heat pipes: From solar to cryogenic applications. Appl. Energy 2018, 222, 475-484. [CrossRef]

34. Zaragoza, G.; Andrés-Mañas, J.; Ruiz-Aguirre, A. Commercial scale membrane distillation for solar desalination. NPJ Clean Water 2018, 1, 20. [CrossRef]

35. Chiavazzo, E.; Morciano, M.; Viglino, F.; Fasano, M.; Asinari, P. Passive solar high-yield seawater desalination by modular and low-cost distillation. Nat. Sustain. 2018, 1, 763. [CrossRef]

36. Chaichan, M.T.; Kazem, H.A.; Abaas, K.I.; Al-Waeli, A.A. Homemade solar desalination system for Omani families. Int. J. Sci. Eng. Res. 2016, 7, 1499-1504.

37. Chandrashekara, M.; Yadav, A. Water desalination system using solar heat: A review. Renew. Sustain. Energy Rev. 2017, 67, 1308-1330.

38. Mashaly, A.F.; Alazba, A.; Al-Awaadh, A. Assessing the performance of solar desalination system to approach near-ZLD under hyper arid environment. Desalin. Water Treat. 2016, 57, 12019-12036. [CrossRef]

39. Ahmadi, M.H.; Ahmadi, M.A.; Bayat, R.; Ashouri, M.; Feidt, M. Thermo-economic optimization of Stirling heat pump by using non-dominated sorting genetic algorithm. Energy Convers. Manag. 2015, 91, 315-322. [CrossRef]

40. Sadatsakkak, S.A.; Ahmadi, M.H.; Bayat, R.; Pourkiaei, S.M.; Feidt, M. Optimization density power and thermal efficiency of an endoreversible Braysson cycle by using non-dominated sorting genetic algorithm. Energy Convers. Manag. 2015, 93, 31-39. [CrossRef]

41. Ahmadi, M.H.; Ahmadi, M.A.; Pourfayaz, F.; Bidi, M. Thermodynamic analysis and optimization for an irreversible heat pump working on reversed Brayton cycle. Energy Convers. Manag. 2016, 110, 260-267. [CrossRef] 
42. Baghban, A.; Kahani, M.; Nazari, M.A.; Ahmadi, M.H.; Yan, W.M. Sensitivity analysis and application of machine learning methods to predict the heat transfer performance of CNT/water nanofluid flows through coils. Int. J. Heat Mass Transf. 2019, 128, 825-835. [CrossRef]

43. Baghban, A.; Jalali, A.; Shafiee, M.; Ahmadi, M.H.; Chau, K.w. Developing an ANFIS-based swarm concept model for estimating the relative viscosity of nanofluids. Eng. Appl. Comput. Fluid Mech. 2019, 13, $26-39$. [CrossRef]

44. Ahmadi, M.H.; Nazari, M.A.; Ghasempour, R.; Madah, H.; Shafii, M.B.; Ahmadi, M.A. Thermal conductivity ratio prediction of $\mathrm{Al} 2 \mathrm{O} 3$ /water nanofluid by applying connectionist methods. Colloids Surf. A Physicochem. Eng. Asp. 2018, 541, 154-164. [CrossRef]

45. Zheng, H.; Zhang, Y.; Liu, J.; Wei, H.; Zhao, J.; Liao, R. A novel model based on wavelet LS-SVM integrated improved PSO algorithm for forecasting of dissolved gas contents in power transformers. Electr. Power Syst. Res. 2018, 155, 196-205. [CrossRef]

46. Sharma, G.; Panwar, A.; Nasiruddin, I.; Bansal, R.C. Non-linear LS-SVM with RBF-kernel-based approach for AGC of multi-area energy systems. IET Gener. Transm. Distrib. 2018, 12, 3510-3517. [CrossRef]

47. Aydogdu, M.; Firat, M. Estimation of failure rate in water distribution network using fuzzy clustering and LS-SVM methods. Water Resour. Manag. 2015, 29, 1575-1590. [CrossRef]

48. Mojumder, J.C.; Ong, H.C.; Chong, W.T.; Shamshirband, S. Application of support vector machine for prediction of electrical and thermal performance in PV/T system. Energy Build. 2016, 111, 267-277. [CrossRef]

49. Malvoni, M.; De Giorgi, M.G.; Congedo, P.M. Data on Support Vector Machines (SVM) model to forecast photovoltaic power. Data Brief 2016, 9, 13-16. [CrossRef]

50. Zhang, Y.; Wang, P.; Ni, T.; Cheng, P.; Lei, S. Wind power prediction based on LS-SVM model with error correction. Adv. Electr. Comput. Eng. 2017, 17, 3-9. [CrossRef]

51. Arabloo, M.; Bahadori, A.; Ghiasi, M.M.; Lee, M.; Abbas, A.; Zendehboudi, S. A novel modelling approach to optimize oxygen-steam ratios in coal gasification process. Fuel 2015, 153, 1-5. [CrossRef]

52. Ahmadi, M.A.; Bahadori, A.; Shadizadeh, S.R. A rigorous model to predict the amount of dissolved calcium carbonate concentration throughout oil field brines: Side effect of pressure and temperature. Fuel 2015, 139, 154-159. [CrossRef]

53. Ahmadi, M.A. Connectionist approach estimates gas-oil relative permeability in petroleum reservoirs: Application to reservoir simulation. Fuel 2015, 140, 429-439. [CrossRef]

54. Suykens, J.A. Least Squares Support Vector Machines; World Scientific: Singapore, 2002.

55. Ahmadi, M.A.; Mahmoudi, B. Development of robust model to estimate gas-oil interfacial tension using least square support vector machine: Experimental and modelling study. J. Supercrit. Fluids 2016, 107, 122-128. [CrossRef]

56. Van Gestel, T.; Suykens, J.A.; Baesens, B.; Viaene, S.; Vanthienen, J.; Dedene, G.; De Moor, B.; Vandewalle, J. Benchmarking least squares support vector machine classifiers. Mach. Learn. 2004, 54, 5-32. [CrossRef]

57. Ahmadi, M.A.; Ebadi, M. Evolving smart approach for determination dew point pressure through condensate gas reservoirs. Fuel 2014, 117, 1074-1084. [CrossRef]

58. Cortes, C.; Vapnik, V. Support-vector networks. Mach. Learn. 1995, 20, 273-297. [CrossRef]

59. Pelckmans, K.; Suykens, J.A.; Van Gestel, T.; De Brabanter, J.; Lukas, L.; Hamers, B.; De Moor, B.; Vandewalle, J. LS-SVMlab: A Matlab/c Toolbox for Least Squares Support Vector Machines; Tutorial; KULeuven-ESAT: Leuven, Belgiumm, 2002; Volume 142, pp. 1-2.

60. Suykens, J.A.; Vandewalle, J. Least squares support vector machine classifiers. Neural Process. Lett. 1999, 9, 293-300. [CrossRef]

61. Ahmadi, M.H.; Ahmadi, M.A.; Ashouri, M.; Astaraei, F.R.; Ghasempour, R.; Aloui, F. Prediction of performance of Stirling engine using least squares support machine technique. Mech. Ind. 2016, 17. [CrossRef]

62. Ahmadi, M.A.; Ebadi, M.; Marghmaleki, P.S.; Fouladi, M.M. Evolving predictive model to determine condensate-to-gas ratio in retrograded condensate gas reservoirs. Fuel 2014, 124, 241-257. [CrossRef]

63. Fazeli, H.; Soleimani, R.; Ahmadi, M.A.; Badrnezhad, R.; Mohammadi, A.H. Experimental study and modelling of ultrafiltration of refinery effluents using a hybrid intelligent approach. Energy Fuels 2013, 27, 3523-3537. [CrossRef] 
64. Curilem, M.; Acuña, G.; Cubillos, F.; Vyhmeister, E. Neural networks and support vector machine models applied to energy consumption optimization in semiautogeneous grinding. Chem. Eng. Trans. 2011, 25, 761-766.

65. Kahani, M.; Ahmadi, M.H.; Tatar, A.; Sadeghzadeh, M. Development of multilayer perceptron artificial neural network (MLP-ANN) and least square support vector machine (LSSVM) models to predict Nusselt number and pressure drop of $\mathrm{TiO}_{2} /$ water nanofluid flows through non-straight pathways. Numer. Heat Transf. Part A Appl. 2018, 74, 1190-1206. [CrossRef]

66. Ahmadi, M.H.; Tatar, A.; Seifaddini, P.; Ghazvini, M.; Ghasempour, R.; Sheremet, M.A. Thermal conductivity and dynamic viscosity modelling of $\mathrm{Fe}_{2} \mathrm{O}_{3}$ / water nanofluid by applying various connectionist approaches. Numer. Heat Transf. Part A Appl. 2018, 74, 1301-1322. [CrossRef]

67. Ahmadi, M.H.; Ahmadi, M.A.; Sadatsakkak, S.A.; Feidt, M. Connectionist intelligent model estimates output power and torque of stirling engine. Renew. Sustain. Energy Rev. 2015, 50, 871-883. [CrossRef]

68. Jefferys, E. Design applications of genetic algorithms. In SPE Annual Technical Conference and Exhibition; Society of Petroleum Engineers: Houston, TX, USA, 1993.

69. Romero, C.; Carter, J. Using genetic algorithms for reservoir characterisation. J. Pet. Sci. Eng. 2001, 31, 113-123. [CrossRef]

70. Ahmadi, M.A. Toward reliable model for prediction Drilling Fluid Density at wellbore conditions: A LSSVM model. Neurocomputing 2016, 211, 143-149. [CrossRef]

71. Ahmadi, M.A.; Ebadi, M.; Samadi, A.; Siuki, M.Z. Phase equilibrium modelling of clathrate hydrates of carbon dioxide+ 1,4-dioxine using intelligent approaches. J.Dispers. Sci. Technol. 2015, 36, 236-244. [CrossRef]

72. Ahmadi, M.A.; Ebadi, M.; Hosseini, S.M. Prediction breakthrough time of water coning in the fractured reservoirs by implementing low parameter support vector machine approach. Fuel 2014, 117, 579-589. [CrossRef]

73. Ali Ahmadi, M.; Ahmadi, A. Applying a sophisticated approach to predict $\mathrm{CO}_{2}$ solubility in brines: Application to $\mathrm{CO}_{2}$ sequestration. Int. J. Low-Carbon Technol. 2016, 11, 325-332. [CrossRef]

74. Ahmadi, M.A.; Shadizadeh, S.R. New approach for prediction of asphaltene precipitation due to natural depletion by using evolutionary algorithm concept. Fuel 2012, 102, 716-723. [CrossRef]

75. Shafiei, A.; Ahmadi, M.A.; Zaheri, S.H.; Baghban, A.; Amirfakhrian, A.; Soleimani, R. Estimating hydrogen sulfide solubility in ionic liquids using a machine learning approach. J. Supercrit. Fluids 2014, 95, 525-534. [CrossRef]

76. Ahmadi, M.A.; Soleimani, R.; Bahadori, A. A computational intelligence scheme for prediction equilibrium water dew point of natural gas in TEG dehydration systems. Fuel 2014, 137, 145-154. [CrossRef]

77. Ahmadi, M.A.; Golshadi, M. Neural network based swarm concept for prediction asphaltene precipitation due to natural depletion. J. Pet. Sci. Eng. 2012, 98, 40-49. [CrossRef]

78. Ahmadi, M.A.; Chen, Z. Analysis of gas production data via an intelligent model: Application to natural gas production. First Break 2018, 36, 91-98.

79. Ahmadi, M.A. Prediction of asphaltene precipitation using artificial neural network optimized by imperialist competitive algorithm. J. Pet. Explor. Prod. Technol. 2011, 1, 99-106. [CrossRef]

80. Ahmadi, M.A.; Masoumi, M.; Askarinezhad, R. Evolving connectionist model to monitor the efficiency of an in situ combustion process: Application to heavy oil recovery. Energy Technol. 2014, 2, 811-818. [CrossRef]

81. Huang, Y.; Huang, G.; Dong, M.; Feng, G. Development of an artificial neural network model for predicting minimum miscibility pressure in $\mathrm{CO}_{2}$ flooding. J. Pet. Sci. Eng. 2003, 37, 83-95. [CrossRef]

82. Emera, M.K.; Sarma, H.K. Use of genetic algorithm to estimate $\mathrm{CO}_{2}$-oil minimum miscibility pressure-A key parameter in design of $\mathrm{CO}_{2}$ miscible flood. J. Pet. Sci. Eng. 2005, 46, 37-52. [CrossRef]

83. Avaullee, L.; Trassy, L.; Neau, E.; Jaubert, J.N. Thermodynamic modelling for petroleum fluids I. Equation of state and group contribution for the estimation of thermodynamic parameters of heavy hydrocarbons. Fluid Phase Equilib. 1997, 139, 155-170. [CrossRef]

84. Madvar, M.D.; Khosropour, H.; Khosravanian, A.; Mirafshar, M.; Azaribeni, A.; Rezapour, M.; Nouri, B. Patent-Based Technology Life Cycle Analysis: The Case of the Petroleum Industry. Popcant 2016, 10, 72-79. [CrossRef]

85. Madavar, M.D.; Nezhad, M.G.; Aslani, A.; Naaranoja, M. Analysis of generations of wind power technologies based on technology life cycle approach. Distrib. Gener. Altern. Energy J. 2017, 32, 52-79. [CrossRef] 
86. Hong, S. The Magic of Patent Information. Available online: https:/ /www.wipo.int/sme/en/documents/ patent_information_fulltext.html (accessed on 11 May 2019).

87. Octaviano, C.; Paltsev, S.; Gurgel, A.C. Climate change policy in Brazil and Mexico: Results from the MIT EPPA model. Energy Econ. 2016, 56, 600-614. [CrossRef]

88. Knoema. Peru- $\mathrm{CO}_{2}$ Emissions per Capita. 2017. Available online: https://knoema.com/atlas/Peru/CO2emissions-per-capita (accessed on 17 March 2019).

89. WorldBank. Moving towards a Sustainable Low-Carbon Economy in Uruguay 2016. Available online: http:/ / www.worldbank.org/en/results /2016/10/13/moving-towards-a-sustainable-low-carboneconomy-in-uruguay (accessed on 17 March 2019).

90. Knoema. Chile- $\mathrm{CO}_{2}$ Emissions per Capita. 2017. Available online: http://www.knoema.com/atlas/Chile/ CO\$2\$-emissions-per-capita (accessed on 17 March 2019).

91. UNFCC. ORIENTAL REPUBLIC OF URUGUAY First Nationally Determined Contribution to the Paris Agreement. 2017. Available online: https://www4.unfccc.int/sites/ndcstaging/Pages/Home.aspx (accessed on 17 March 2019).

92. BrazilGovNews. Brazil Will Reduce Greenhouse Gas Emissions in 10\% by 20282018.2017. Available online: http:/ /www.brazilgovnews.gov.br/news/2018/06/brazil-will-reduce-greenhouse-gasemissionsin-10-by-2028 (accessed on 17 March 2019).

93. Santos, L.; Garaffa, R.; Lucena, A.; Szklo, A. Impacts of Carbon Pricing on Brazilian Industry: Domestic Vulnerability and International Trade Exposure. Sustainability 2018, 10, 2390. [CrossRef]

94. Rojas-Cardenas, J.C.; Hasanbeigi, A.; Sheinbaum-Pardo, C.; Price, L. Energy efficiency in the Mexican iron and steel industry from an international perspective. J. Clean. Prod. 2017, 158, 335-348. [CrossRef]

95. Hübner, C. Climate Report 2017: Argentina; Technical Report; Konrad Adenauer Stiftung. Available online: https:/ / www.kas.de/single-title/- / content/klimareport-2017-argentinien (accessed on 11 May 2019).

96. IEA. Argentina Renewable Energy Auctions; Technical Report, RenovAr Program (Round 1). Available online: https:/ / www.iea.org/policiesandmeasures/pams/argentina/name-158884-en.php (accessed on 11 May 2019).

97. Fernandez, V. Copper mining in Chile and its regional employment linkages. Resour. Policy 2018. [CrossRef]

98. Maxwell, A.; Herrera, C. Acting Now on Climate: How is Peru Addressing Climate Change and Moving toward a Low-Carbon Future? NRDC Issue Brief. Available online: https: / www.nrdc.org/resources/actingnow-climate-how-peru-addressing-climate-change-and-moving-toward-low-carbon-future (accessed on 11 May 2019).

(C) 2019 by the authors. Licensee MDPI, Basel, Switzerland. This article is an open access article distributed under the terms and conditions of the Creative Commons Attribution (CC BY) license (http://creativecommons.org/licenses/by/4.0/). 